\title{
Bacterial profile of ocular infections: a systematic review
}

\author{
Mebrahtu Teweldemedhin ${ }^{1 *}$, Hailay Gebreyesus ${ }^{2}$, Ataklti Hailu Atsbaha ${ }^{3}$, Solomon Weldegebreal Asgedom ${ }^{4}$ and \\ Muthupandian Saravanan ${ }^{5}$
}

\begin{abstract}
Background: Bacteria are the major contributor of ocular infections worldwide. Ocular infections, if left untreated, can damage the structures of the eye with possible blindness and visual impairments. This work was aimed to review the bacterial profile of ocular infections.

Methods: Literature search was made in different electronic databases; the review was systematically made to get concrete findings.

Results: As far as this review, Staphylococcus aureus, Coagulase negative Staphylococci, Streptococcus pneumoniae and Pseudomonas aeruginosa are the leading isolates in ocular infections. Frequent pathogens of the respective clinical diagnose include Staphylococci, Streptococcus pyogenes and Pseudomonas aeruginosa in blepharitis; Staphylococci, Streptococus pneumoniae, Pseudomonas aeruginosa, Klebsiella pneumoniae and Escherichia coli in Conjunctivitis; Staphylococci, P. aeruginosa and E. coli in dacryocystitis; Coagulase negative Staphylococci, Pseudomonas aeruginosa and Staphylococcus aureus in keratitis; Streptococcus viridians, Streptococcus pneumoniae and Coagulase negative Staphylococci in endophthalmitis diagnoses. Endogenous endophthalmitis is associated with Klebsiella pneumoniae whereas Coagulase negative Staphylococci and Bacillus spp. are common causes of post-operative and post-traumatic endophthalmitis. However, the predominant pathogens may not be exactly same in all areas of the world, in the United States for instance, Staphylococcus aureus, Streptococcus pneumoniae and Haemophilus influenzae are the major causes of conjunctivitis.

Conclusion: Gram positive bacteria are the major contributor of bacterial ocular infections. The distribution and proportion of bacterial isolates among clinical diagnoses varied but without exclusive anatomical restriction. To mitigate the burden of bacterial ocular infections, physicians should regard on risk reduction and comply with etiologic approach of diagnosis.
\end{abstract}

Keywords: Ocular infection, Bacterial profile, Review

\section{Background}

Bacteria are the major contributor of ocular infections worldwide. Infection can be mono or poly-microbial and is associated with many factors including contact lenses, trauma, surgery, age, dry eye state, chronic nasolacrimal duct obstruction and previous ocular infections [1-3]. Bacteria are generally associated with many types of ocular infections such as conjunctivitis, keratitis, endophthalmitis, blepharitis, orbital cellulitis and dacryocystitis manifestations [4].

Conjunctivitis, inflammation of the mucosa of conjunctiva, is the most frequent ocular case with noticeable

\footnotetext{
*Correspondence: mebrie1216@gmail.com

${ }^{1}$ Department of Medical Laboratory Sciences, College of Health Sciences,

Aksum University, Aksum, Tigray, Ethiopia

Full list of author information is available at the end of the article
}

economic and social burdens [5]. During chronicity, the disease can affect not only the conjunctiva but also adjacent structures including the eye lid and can be a potential risk for other extra or intraocular infections. Bacteria contribute for about $50-70 \%$ of infectious conjunctivitis [6]. Bacterial conjunctivitis is commonly seen in children and the elders but can also be presented among neonates and adults $[7,8]$.

Blepharitis which is an inflammation of the eyelid can cause loss of eye lash [9]. The infection may not remain localized and is known to spread to other anatomical sites of the eye [10]. Keratitis, the most serious eye infection is the leading cause of corneal blindness. Moreover, the disease can also progress to endophthalmitis if not diagnosed early [11-13]. 
Exogenous endophthalmitis is an infective complication of primary cataract, intraocular surgery and ocular trauma due to the introduction of infectious pathogens like bacteria whereas the endogenous one is commonly due to systemic dissemination of the pathogens. Both keratitis and endophthalmitis are potentially devastating ocular infections if not diagnosed early [14-16].

Dacryocystitis is an inflammation of the nasolacrimal duct. During chronicity the disease is associated with infection, inflammation of the conjunctiva, accumulation of fluid and chronic tearing. This can be potentially dangerous to ocular tissues such as the cornea; leading to post surgery endophthalmitis $[17,18]$.

Ocular infections, if left untreated, can damage the structures of the eye leading to visual impairments and blindness. Even though the eye is hard and protected by the continuous flow of tear which contains antibacterial compounds, inflammation and scarring once occurred may not be easily resolved and requires immediate management [10]. Effective management of such infections demands knowledge of the specific etiology. However, ocular infections are mostly managed empirically and little is known about the specific bacterial etiologies [19, 20]. Therefore, the main goal of this work was to review the bacterial profile of the different forms of ocular infections in order to come up with concrete information for physicians and policy makers who deals with ocular infections.

\section{Methods}

The literature search was made in Electronic data base such as PubMed and Google scholars based on the key words of bacterial infection, bacterial profile, microbial spectrum, eye infections and ocular infections. Studies published until 2016 and emphasizing on external and internal ocular infections were subjected to systematic review and those that are close to the review objectives were included from different parts of the world to get concrete findings ( 76 out of 145); articles written and published in English language, emphasizing on any of the external-ocular infections (dacryocystitis, orbital cellulites, blepharitis, conjunctivitis and keratitis) and internal-ocular (endophthalmitis) infections were included in the study. Articles written other than English language, lacking full length forms and articles published before 1999 were excluded from this review.

\section{Result}

The distribution and types of bacteria in ocular infections Gram positive bacteria

According to the studies conducted so far Gram positive bacteria are associated with variety of ocular infections. The most commonly reported isolates belong to the genus Staphylococci regardless of the study area and population (see Table 1). Staphylococci are associated with any type of eye infections including conjunctivitis, blepharitis, endophthalmitis, keratitis, dacryocystitis and orbital cellulitis; most importantly with blepharitis, conjunctivitis and keratitis [10, 21]. Both S. aureus (Staphylococcus aureus) and CoNS (Coagulase-negative Staphylococci) took the highest proportion of the isolates [2, 22].

Despite their normal existence, CoNS are the most frequent cause of ocular infections with increasing frequencies over time [23]. A 5 year retrospective study in Iran indicated that $40 \%$ of infections were due to CoNS [24]. A Similar study in India also found a prevalence of $45.4 \%$ [25]. The problem is worse especially in preoperative and post-operative cases. In a study conducted in patients with cataract surgery, $88.8 \%$ of isolates from conjunctival swabs were CoNS [26]. Likewise, $65.9 \%$ and $21 \%$ of pre-operative cataract patients had CoNS and $S$. aureus isolates respectively. Considering the specific species, S. epidermidis and S. saprophyticus were the common species of CoNS [27]; both species being dominant in subjects with post-operative endophthalmitis as to the study conducted over 20 years in China [28]. In general Staphylococcal infection is common in both post infection and post-operative endophthalmitis cases [29, 30]. Moreover, S. aureus and S. epidermidis are known to be the common cause of early onset bleb-associated endophthalmitis [31].

S. aureus is also the threat of eye infection and has been showing significantly increasing trends over time [32]. Among patients with symptoms of conjunctivitis in Nigeria, it was the leading isolate [2]. Comparable findings were also reported in Ethiopia; S. aureus was isolated from $47.6 \%$ of blepharitis, $26.6 \%$ of conjunctivitis, and $25 \%$ of keratitis cases [21]. As in the other clinical cases, it is also common to find both MSSA (Methicillin-sensitive Staphylococcus aureus) and MRSA (Methicillin-resistant Staphylococcus aureus) in ocular infections. Studies indicated that $47.8 \%$ of patients with sight-threatening disorders, $24.5 \%$ of lid disorders as well as $10.6 \%$ of lacrimal disorders have been infected with MRSA. Hospital acquired MRSA has been involved in Ocular infections in association with health care exposure and ophthalmic surgeries [33, 34]. Tsironi et al. from Greece reported community-acquired MRSA from a young Infant with orbital cellulitis. Upon the microbiological analysis, the isolate was found to be ST80 strain with Panton-valentine leukocidin [35]. Even though the prevalence of $S$. aureus is higher in conjunctivitis diagnoses, MRSA infection was found to be higher in endophthalmitis and keratititis diagnoses [32]. In Taiwan however, MRSA keratitis was $36.1 \%$ followed by conjunctivitis $20.1 \%$ and endophthalmitis $3.3 \%$ [33].

Despite their small proportion, members of the genus Streptococci including S. pneumoniae (Streptococcus pneumoniae), S. Pyogenes (Streptococcus pyogenes), Enterococcus and S. viridians (Streptococcus viridians) 
Table 1 Overall proportion of common bacterial isolates in ocular infection

\begin{tabular}{|c|c|c|c|c|c|c|c|c|c|c|c|}
\hline \multirow{3}{*}{$\begin{array}{l}\text { References, } \\
\text { country }\end{array}$} & \multicolumn{11}{|c|}{$\%$ of bacterial isolates } \\
\hline & \multicolumn{4}{|c|}{ Gram positive } & \multicolumn{7}{|l|}{ Gram negative } \\
\hline & S. aureus & CoNS* & S. pyogens & S. pneumoniae & P. aeruginosa & E. coli & K. pneumoniae & Proteus spp & H. influenzae & Moraxella spp & N. gonorrhoeae \\
\hline [10], Nigeria & 23.7 & 19.2 & 6.2 & 8.6 & 10.1 & 4.4 & 6.2 & 1.5 & 7.7 & 3 & 3.9 \\
\hline [22], India & 13 & 37 & & & 21 & 3 & 7 & & & & \\
\hline [21], Ethiopia & 28.1 & 10.1 & & 13.5 & 20.9 & 5.4 & & & 8.8 & 4 & 2.7 \\
\hline$[46]$, India & 26.6 & 6.1 & 1.6 & 22.14 & 8.23 & 0.9 & & 0.6 & 3.45 & 5.4 & 0.42 \\
\hline [53], Japan & 21 & 31.4 & & 3.2 & 9.7 & & 2.4 & 1.6 & 2.4 & 0.8 & \\
\hline [50], India & 24.6 & 19.8 & & 4.9 & 16 & 12.3 & 4.9 & & 4.9 & & \\
\hline [57], Iran & 12.9 & 32.9 & & 8.6 & & & & & & & \\
\hline [75], India & 19.13 & 20.76 & 0.55 & 20.76 & 4.92 & 1.1 & 2.74 & 0.33 & & 19.13 & 20.76 \\
\hline [65], Ethiopia & 21 & 27.4 & 14.5 & 11.3 & & 8.1 & 14.5 & & & & \\
\hline [76], India & 32.8 & 39 & & 14.1 & 3 & 4.7 & 6.2 & & & & \\
\hline [77], Ethiopia & 21 & 18.2 & 4.2 & 14 & 4.9 & 4.9 & 6.3 & 3.4 & 4.2 & 2.8 & \\
\hline [78], USA & 19 & 25 & & & 8 & 8 & 10 & & & & \\
\hline [79], Malaysia & 17 & & 3.1 & & 16 & 4 & 5.5 & & 8.3 & & \\
\hline [80], USA & 22.1 & 6.7 & & 2.4 & 13.7 & & & & 2.3 & & \\
\hline Average & 20.1 & 19.5 & 4.3 & 6.7 & 12 & 5.9 & 7.7 & 1.5 & 5.3 & 3.2 & 2.3 \\
\hline
\end{tabular}

Note: CoNS* ${ }^{*}$ Coagulase Negative Staphylococci

have been involved in ocular infection and had worse outcomes than the Staphylococcal infection especially in post-cataract endophthalmitis $[4,36]$.

Around $80 \%$ of Streptococcal post injection endophthalmitis cases had final or worse visual outcomes. Moreover, Streptococcal infection is 3 times more prevalent in post injection than post operation endophthalmitis suggesting the possibility of contamination by nasopharyngeal floras during the process of injection [16].

Streptococcal infection is also common in bleb associated endophthalmitis especially in the early onset bleb-associated endophthalmitis. One study from USA reported that 23\% and $65 \%$ of isolates from bleb-associated endophthalmitis were $S$. pneumoniae and $S$. viridians respectively while other $\beta$-hemolytic Streptococci contributed for $12 \%$ of the infection [37]. Like S. aureus and some gram negatives, S. pneumoniae and $S$. pyogenes also reported to causing hospital acquired infections mainly conjunctivitis in neonates with intensive care unit [38]. Even though they are not as common as $S$. pneumoniae, S. pyogenes, S. viridians and E. faecalis (Enterococcus faecalis) were also reported in blepharitis, conjunctivitis and keratitis cases [10, 23, 39].

$S$. pneumoniae, the most pathogenic and fastidious Streptococcus is among the common isolates in patients with conjunctivitis and dacrocystitis [40-42]. The bacterium is not limited only to these types of infections. Even though it is not as common as CoNS, studies supported the occurrence of the bacteria in eyelid and conjunctival samples of patients with pre-cataract surgery [27]. In a study conducted in India, $12.3 \%$ of bacterial keratitis was mainly Streptococcal comprised of $11.6 \%$ S. pneumoniae and $0.6 \%$ S. viridians [39]. Studies implicated that keratitis due to S. pneumoniae is more often associated with permanent loss of vision [43].
Upper respiratory tract infections of Streptococcal and Staphylococcal origin are sometimes associated with orbital cellulitis and other complications. For instance, orbital cellulitis, endophthalmitis and acute pan-sinusitis was reported as a complication of Streptococcal pharyngitis due to $S$. pyogenes [44]. In addition, it is common to find S. pneuomoniae and S. aureus from specimens of sub periosteal abscess [44]. Because S. pneumoniae is a normal inhabitant of the Nasopharynx especially in children, immunization may be needed to reduce the spread to other sites including the eye. Clinical trials in a rabbit model assured that passive immunization can neutralize pneumococcal virulence and remarkably minimize the severity of endophthalmitis [45].

Gram positive bacilli are also known to cause ocular infections. According to the study conducted in Nigeria, Gram positive bacilli accounted for $22.6 \%$ of conjunctivitis cases amongst Corynebacterium species were predominant followed by Bacillus species [2]. Corynebacterium infection is higher in blepharitis and conjunctivitis diagnoses; $35.7 \%$ and $35.3 \%$ of Corynebacterium isolates respectively [46]. Not only this, Corynebacterium species have also been reported in both acute and chronic dacryocystitis [18]. As compared to the other clinical presentations, Bacillus species are more prevalent in conjunctivitis and post-traumatic endophthalmitis [46, 47]. In addition, both groups have been involved in bacterial keratitis (Bacillus species accounted for $5.3 \%$ of isolates but $0.3 \%$ of the isolates were Corynebacterium diphtheria) [39]. Among Bacillus species, B. cereus (Bacillus cereus) is the major one (56.2\%) followed by B. thuringiensis (Bacillus thuringiensis) 26.3\%, B. subtilis (Bacillus subtilis), B. mycoides (Bacillus mycoides) and B. pumilis (Bacillus pumilis) 5.2\% each; B flexus (Bacillus 
flexus) 2.6\% [48]. Less commonly, one study from India reported Clostridium species from endophthalmitis cases [49].

\section{Gram negative bacteria}

Studies from different parts of the world indicated that diverse group of Gram negative bacteria are isolated from ocular infections (see Table 1). Among Gram negatives, frequent isolates of conjunctivitis include $P$. aeruginosa (Pseudomonas aeruginosa), E. Coli (Escherichia coli), Enterobacter spp. (Enterobacter cloacae and Enterobacter aerogenes), C. koseri (Citrobacter koseri), Proteus spp., Moraxella spp., and N. gonorrhoeae (Neisseria gonorrhoeae) $[2,38,50]$.

In patients presented with dacryocystitis, Pseudomonas spp., Enterobacter, K. pneumoniae (Klebsiella pneumoniae) and $H$. influenza (Haemophilus influenza) were reported as the main Gram negative isolates [40]. In addition, another study in Egypt reported isolates of $E$. coli and A. lwoffii (Acinetobacter lwoifi) from chronic dacryocystitis cases [18].

In keratitis diagnoses, $P$. auroginosa, E. coli, K. pneumoniae, Acinetobactor, Serratia (S. marcescens and S. liquefaciens), Aeromonas, Fusobacterium, Enterobactor spp., P. mirabilis (Proteus mirabilis), P. multocida (Pasteurella multocida), M. catarrhalis (Moraxella catarrhalis) and $H$. influenza have been reported [23, 39, 43]. In addition, Propiolactone species have been reported in small prevalence but higher in chronic post-operative endophthalmitis (41-63\%). M. catarrhalis is also among the common cause of delayed onset bleb-associated endophthalmitis [23, 51]. Unexpectedly, polymicrobial infection was seen in any type of endophthalmitis (postoperative, post-traumatic as well as endogenous); isolates include Serratia spp., P. aeruginosa, K. pneumoniae, Enterobacter, Acinetobacter, and Haemophilus spp. Moreover, new Gram positive agents (Pantoea spp. and Massilia spp.) have been reported [49].

$M$. catarrhalis is an opportunistic pathogen which commonly affects immune compromised individuals and alcohol addicts. The organism preferentially affects the eye especially the cornea but rarely other organs. Despite its sluggish microbiological activity it can damage the cornea badly as similar to other virulent pathogens and should be considered as one of the major ocular threats [52]; it results in necrosis and perforation of the cornea due to the deepening keratitis and hyperacute inflammatory reaction. In children, $M$. catarrhalis and H. influen$z a e$ are common causes of Gram negative bacterial conjunctivitis. However, both species have also been isolated from endophthalmitis and orbital cellulitis cases [53]. According to the retrospective study conducted in India, $M$. catarrhalis (53.17\%) and M. lacunata (63.83\%) infection was significantly higher in blephratis and dacryocytitis diagnoses respectively. Similarly, $73.2 \%$ of $H$. influenzae isolates were from conjunctivitis and dacryocystitis diagnoses [46]. The distribution of $H$. influenzae biotypes in ocular diagnoses is noticeably different; biotype II in blepharitis, conjunctivitis, and keratitis; biotype III common in conjunctivitis, keratitis and dacryocystitis; biotype VII only being detected in keratitis diagnoses [54]. H. influenzae being the most frequent isolate, small numbers of $H$. parainfluenzae and $H$. aegypticus has also been detected in dacryocystits as to the study from India [46].

$\mathrm{N}$. gonorrhoeae, the Gram negative diplococcic, is the common cause of neonatal conjunctivitis though reported in keratitis cases too. Unlike other cases of conjunctivitis, involvement of this bacterium needs early treatment with topical antibiotics. N. gonorhoeae infection happens most commonly vertically. A prospective study in Angola realized that vertical transmission rate of $N$. gonorrhoeae was $50 \%$ whereas $10.5 \%$ for M. genitalium (Mycoplasma genitalium) [55]. As far as this review no study reported the occurrence of $N$. meningitis in ocular infections except the one case detected in Nigeria from a child with conjunctivitis and three cases from India $[10,46]$.

P. aeruginosa is the most frequent isolate of Gram negative ocular infections [22]. The percentage of the organism varied among clinical diagnoses of ocular infections but the common cause of bacterial keratitis which is more progressive with large infiltrate and scarring $[43,56]$. A study from India supported the significantly higher proportion of the bacteria in dacryocystitis and keratitis manifestations [46]. As to the study conducted in Ethiopia, $P$. aeruginosa isolates were $50 \%$ of keratitis diagnoses followed by blepharitis (23.8\%), conjunctivitis (11.4\%) and blepharoconjunctivitis (16.7\%) [21].The reported figure does note that much vary among older and recent works. In Iran for instance, the organism constituted $24.2 \%$ of ocular infections [57]. Comparable finding even in studies conducted for extended periods is indicative of the continuous Pseudomonas corneal attacks [23]. A 4 years study by Patel et al. convinced the predominance of $P$. aeruginosa in keratitis diagnoses (more than 40\%) but 20\% in other clinical diagnoses [58]. As to Ly et al. from Australia 21\% of isolates from keratitis cases were entirely $P$. aeruginosa [59]. Similarly, in a study conducted in 2014-2015 in Baghdad P.aeruginosa was detected in $20 \%$ of eye specimens collected from symptomatic patients [60]. Furthermore, a published case report from Spain revealed that $P$. aeruginosa caused ocular necrotizing fasciitis. The diagnosis was made in a 53 old male patient who presented with eyelid edema and purulent secretion in both eyes. The prognosis report indicated that the Infection did get worse and involved pre orbital skin regardless of the antibiotic and surgical managements [61]. 
Ocular infection by $K$. pneumoniae is most commonly endogenous spread after liver abscess or biliary tract infection. The organism accounts for up to $60 \%$ of bacterial endophthalmitis [62]. Endogenous endophthalmitis due to this organism can rapidly cause complete loss of vision [63]. Moreover, studies supported the involvement of the bacterium in any of the other clinical manifestations (blepharitis, conjunctivitis, keratitis and dacryocystitis) (see Tables 2 and 3). Even though $K$. pneumoniae is the most frequent one, $K$. oxytoca (Klebsiella oxytoxa) has also been reported in $2 \%$ of bacterial keratitis [59].

\section{Other less commonly encountered and newly reported organisms}

Studies implicated that P. maltocida has been noticed in a case with purulent conjunctivitis in association with animal contact with a domestic dog being the suspected animal which contaminated an old man after sneezing [64]. Another newly identified organism is S. maltophilia (Stenotrophomonas maltophilia), an aerobic gram negative bacterium formerly identified as Pseudomonas maltophilia. According to the study conducted in China, this organism was detected in $36 \%$ of patients with post cataract surgery. Infection was accompanied with complications (retinal detachment and recurrence) and statistically associated with age and posterior capsule rupture [63].

Micrococcus, the Gram positive organism contributed to $4.3 \%$ of ocular infections in a study conducted in Iran [57]. Furthermore, a study which targeted endophthalmitis cases has revealed new Gram positive agents including Lysinebacillus, Gemella and Exiguobacterium species [49].

\section{Discussion}

The summary of literatures in this review indicated that both gram positive and Gram negative bacteria can cause eye infections. Gram positive bacteria are the leading cause of ocular bacterial infections elsewhere [22, 23, 28, 65]. As compared to Gram positives, Gram negative bacteria are less prevalent but more diverse than Gram positive pathogens [53]. Specifically, S. aureus, CoNS, S. pneumoniae and $P$. aeruginosa are the leading isolates in ocular infections. Frequent pathogens of the respective clinical diagnose include Staphylococci, $S$. pyogenes and P. aeruginosa in blepharitis; Staphylococi, S. pneumoniae, $P$. aeruginosa, $K$. pneumoniae and E. coli in Conjunctivitis; Staphylococci, P. aeruginosa and E. coli in dacryocystitis; CoNS, $P$. aeruginosa and $S$. aureus in keratitis; S. viridians, S. pneumoniae and CoNS in endophthalmitis diagnoses. However, there may be some differences in the leading type of bacterial isolates in some parts of the world. In the United States of America for instance, acute conjunctivitis is the most common ocular infection in outpatient healthcare settings and the most common bacterial causes are S. aureus, $H$. influenzae, S. pneumoniae and $M$. catarrhalis $[7,66]$. S. aureus is the common cause of conjunctivitis in adults but $S$. pneumoniae and $H$. influenzae are the most frequent causes of bacterial conjunctivitis in Children [66].

The distribution of each bacterial isolate among the different type of ocular infections might be determined by variety of factors. For instance, ocular surface disease and contact lens use have been strongly associated with bacterial keratitis; the inflammatory reaction and anatomical disruption might be a good opportunity for some normal floras such as members of the Staphylococci to elicit infection. Moreover, infections might be attributed to traumatic inoculation of the organisms along with foreign bodies and delayed repair secondary to trauma [67]. This has been evidenced in post-traumatic infections of Staphylococci, Streptococci, B. cereus and

Table 2 Proportion of frequent bacterial isolates in keratitis diagnoses

\begin{tabular}{|c|c|c|c|c|c|c|c|c|c|c|}
\hline \multirow{3}{*}{$\begin{array}{l}\text { References, } \\
\text { country }\end{array}$} & \multicolumn{10}{|c|}{$\%$ of bacterial isolates } \\
\hline & \multicolumn{5}{|c|}{ Gram positive } & \multicolumn{5}{|l|}{ Gram negative } \\
\hline & S. aureus & CONS* & S. pneumoniae & S. viridians & Bacillus spp. & P. aeruginosa & E. coli & K. pneuoniae & Proteus spp. & H. influenzae \\
\hline [10], Nigeria & 22.4 & 22.4 & 3 & 1.5 & & 22.4 & 22.4 & & & 4.5 \\
\hline [23], UK & 14.2 & 25.8 & 3 & 0.4 & 0.4 & 24.3 & & 0.4 & & 0.7 \\
\hline [27], Uganda & 20.5 & 66.6 & 1.3 & & & & & & & \\
\hline [39], India & 19.5 & 20.2 & 11.6 & 0.6 & 5.2 & 9.7 & & 0.99 & & \\
\hline [59],Australia & 11 & 38 & & & & 21 & & & & \\
\hline [81], Iran & 3.85 & 6.2 & 24.7 & 6.6 & 0.55 & 24.7 & 0.55 & & 0.55 & \\
\hline [67], Mexico & 7.1 & 28.1 & 14.3 & 14.3 & & 14.3 & & & & \\
\hline [82], Israel & 10 & & 14 & & & 16 & & & & 3 \\
\hline [83], France & 5.2 & 32.7 & 2.3 & & & 6.8 & & & 0.7 & \\
\hline [84],Thailand & 2 & 11 & & & 2 & 55 & & 2 & 2 & 2 \\
\hline [85], Brazil & 5.9 & 4.4 & $2.4^{a}$ & & & 7.7 & & 0.6 & 0.6 & \\
\hline
\end{tabular}


Table 3 Comparative distribution of bacterial pathogens in clinical diagnoses other than keratitis

\begin{tabular}{|c|c|c|c|c|c|c|c|c|c|c|c|c|c|c|c|c|}
\hline \multirow[b]{3}{*}{ Reference } & & & \multicolumn{14}{|c|}{ Type of Clinical diagnose } \\
\hline & & & \multicolumn{2}{|c|}{ Blephritis } & \multicolumn{7}{|c|}{ Conjunctivitis } & \multicolumn{2}{|c|}{ Dacryocystitis } & \multicolumn{3}{|c|}{ Endophthalmitis } \\
\hline & & & [10] & {$[21][77]$} & {$[2]$} & {$[10]$} & {$[27]$} & {$[38]$} & [74] & {$[86]$} & {$[69]$} & [18] & [40] & {$[37]$} & [49] & {$[74]$} \\
\hline \multirow[t]{17}{*}{$\%$ of bacterial isolates } & Gram positive & S. aureus & 45.5 & 32 & 27.1 & 20.3 & 21.7 & 8.2 & 52.5 & 5 & 26 & 50 & 19.4 & & & 12.5 \\
\hline & & CoNS* & 22.7 & 35.6 & 22.6 & 18 & 65 & & 30.1 & 83.1 & 45.4 & 52.2 & 29 & & 10.5 & 18.8 \\
\hline & & S. pyogenes & 13.6 & 3.6 & & 5.7 & & & & & & & & & & \\
\hline & & S. pneumoniae & 9 & 3.6 & & 10.4 & 5 & 1.6 & & & & & 6.5 & 21 & 21 & 31.3 \\
\hline & & S. viridians & 2.3 & 3.6 & & 4.5 & & & & 1.7 & & & & 71 & 10.5 & \\
\hline & & Enterococcus & & & & 2.25 & & & & 1.7 & & & & & & \\
\hline & & Bacillus spp. & & & & & & & & 0.9 & & & & & 10.5 & \\
\hline & Gram negative & $P$. aeruginosa & & 23.8 & 9.7 & 8.5 & & 18 & & 2.5 & 1.6 & 37.5 & & & 21 & \\
\hline & & E. coli & & 3.6 & 6.5 & 0.45 & & 23 & & 0.9 & & & & & & \\
\hline & & K. pneumoniae & 6.8 & & & 6.8 & & 9.8 & 2.6 & 0.4 & 2.8 & 17.4 & 6.5 & & 5.25 & 12.5 \\
\hline & & Serratia & & 4.8 & & & & 28 & & & & & & & & \\
\hline & & Acinetobacter & & & & & & & & & & & & & 5.25 & \\
\hline & & Enterobacter & & & 1.9 & & & 13 & & & & & 6.5 & & & \\
\hline & & Proteus & & 3.6 & & 2.25 & & 1.9 & 5.14 & & 1.6 & & & & & 6.2 \\
\hline & & H. influenzae & & 4.8 & & 10.4 & & & & & & & 6.5 & & 5.25 & \\
\hline & & M. catarrhalis & & 9.5 & 4.5 & 4.5 & & & & 0.4 & & & & & & 12.5 \\
\hline & & N. gonorrhoeae & & & & 5.4 & & & & & & & & & & \\
\hline
\end{tabular}

Note: Country of the references: 2 (Nigeria); 10 (Nigeria); 18 (Egypt); 21, 40 \&77 (Ethiopia); 27 (Uganda); 37 (USA); 38 (Portugal); 49 (India); 74 (Pakistan); 86 (India); 69 (Colombia); ${ }^{*}$ CoNS $=$ Coagulase Negative Staphylococci

many other gram negative organisms mentioned in this review $[28,68]$. Bacteria such as $P$. aeruginosa are resistant to lens cleaning solutions where they adhere and spread through the formation of lipid rafts in contact lens users $[12,69,70]$.

In Individuals with underlying disease such as diabetic mellitus and rheumatoid arthritis, the diminished immunity may result in loss of control of systemic infections with subsequent spread to ocular tissues especially in endophthalmitis [62, 71]. This has also been evidenced in case of $K$. pneumoniae endophthalmitis infections and $M$. catarrhalis keratitis infections [72, 73] In addition, age might be a factor due to waning immunity and susceptibility to bacterial ocular infections [13, 74]. Operative procedures, prophylactic measures and topical use of corticosteroids are also good predisposing factors for bacterial ocular infections associated with the immune suppression and inability to kill some organisms like $P$. aeruginosa and $S$. epidermidis $[12,59]$. Because many of the bacteria in this review are nosocomial pathogens, infections might have also been explained by hospitalization and intensive use of medical devices [69]. This has been supported by some other studies in that many organisms including MRSA, S. marscecence, $P$. aeruginosa and $E$. coli were associated with hospital acquired neonatal ocular infections [34, 38]. In general, each bacterium can possibly affect the different ocular structures but the frequency of infection largely depends on the type of predisposing factors. This study reviewed the bacterial profile of externalocular as well as intra-ocular infections; as a limitation Chylamydia trachomatis was not included in this review.

\section{Conclusion}

Both Gram positive and Gram negative bacteria are threats of ophthalmic tissues. However, Gram positive bacteria are the major contributor of ocular infections. Bacterial ocular infection involves but is not limited to blepharitis, conjunctivitis, keratitis, endophthalmitis, and orbital cellulitis. The distribution and proportion of bacterial isolates varied among the different clinical diagnoses but without exclusive anatomical restriction. To mitigate the burden of bacterial ocular infections, physicians should regard on risk reduction and comply with etiologic approach of diagnosis.

\section{Abbreviations \\ CoNS: Coagulase negative Staphylococci; MRSA: Methicillin Resistant Staphylococcus aureus}

\section{Acknowledgements}

We would like to acknowledge Mekelle University College of health sciences and Aksum University College of Health Sciences and Referral Hospital for the internet access.

Funding

This review was not supported by any funding agent. 


\section{Availability of data and materials}

The datasets supporting the conclusions of this review are included in the article.

\section{Authors' contributions}

MT conceived, reviewed and wrote the manuscript. MS conceived and supervised the review. HG, SW and AH participated in the design, literature review, manuscript writing and editing. All authors read and approved the final manuscript

\section{Authors' information}

MT: Medical Microbiologist and lecturer at Aksum university college of Health Sciences and Referral hospital, Ethiopia.

HG: Health Education and Promotion and lecturer at Aksum university college of Health Sciences and Referral hospital, Ethiopia.

SW: Clinical pharmacist and lecturer at Mekelle University College of health science, Ethiopia.

AH: Medical Microbiologist, Tigray Health and Research Laboratory, Ethiopia. MS: Associate professor at Mekelle University, College of Health Sciences, Institute of Biomedical Sciences, Department of Medical Microbiology and Immunology, Ethiopia.

\section{Ethics approval and consent to participate}

Not applicable.

\section{Consent for publication}

Not applicable.

\section{Competing interests}

The authors declare that they have no competing interests.

\section{Publisher's Note}

Springer Nature remains neutral with regard to jurisdictional claims in published maps and institutional affiliations.

\section{Author details}

'Department of Medical Laboratory Sciences, College of Health Sciences, Aksum University, Aksum, Tigray, Ethiopia. ${ }^{2}$ Department of Public health, College of Health Sciences, Aksum University, Aksum, Tigray, Ethiopia. ${ }^{3}$ Tigray Health and Research Laboratory, Mekell, Tigray, Ethiopia. ${ }^{4}$ Department of Clinical Pharmacy, School of Pharmacy, College of Health Sciences, Mekelle University, Mekelle, Tigray, Ethiopia. ${ }^{5}$ Department of Medical Microbiology and Immunology, Institute of Biomedical Sciences, College of Health Sciences, Mekelle University, Mekelle, Tigray, Ethiopia.

\section{Received: 2 February 2017 Accepted: 16 November 2017}

\section{Published online: 25 November 2017}

\section{References}

1. Galvis V, Tello A, Guerra A, Acuna MR, Villarreal D. Antibiotic susceptibility patterns of bacteria isolated from keratitis and intraocular infections at Fundación Oftalmológica de Santander (FOSCAL), Floridablanca, Colombia. Biomedica. 2014;34(1):23-33.

2. Iwalokun A, Oluwadun A, Akinsinde A. Niemogha and Nwaokorie O Bacteriologic and plasmid analysis of etiologic agents of conjunctivitis in Lagos, Nigeria. J Ophthal Inflamm Infect. 2011;1:95-103.

3. Choudhury R, Panda S, Sharma S and Sidh V. Staphylococcal infection, antibiotic resistance and therapeutics, antibiotic resistant bacteria - a continuous challenge in the new millennium, Dr. Marina Pana (Ed.) 2012, ISBN: 978-953-51-0472-8.

4. Bertino S. Impact of antibiotic resistance in the management of ocular infections: the role of current and future antibiotics. Clin Ophthalmol. 2009; 3:507-21.

5. Cervantes J, Mah S. Clinical use of gatifloxacin ophthalmic solution for treatment of bacterial conjunctivitis. Clin Ophthalmol. 2011;5:495-502.

6. Buznach N, Dagan R, Greenberg D. Clinical and bacterial characteristics of acute bacterial conjunctivitis in children in the antibiotic resistance era. Pediatr Infect Dis J. 2005;24:823-8.

7. Hovding G. Acute bacterial conjunctivitis. Acta Ophthalmol. 2008;86(1):5-17.

8. Dawood A, Ahmad K. Antibiotic resistance patterns of ocular surface bacterial Flora. J Infect Dis Antimicrob Agents. 2005;22(2):53-6.
9. Kowalski RP, Dhaliwal DK. Ocular bacterial infections: current and future treatment options. Expert Rev Anti-Infect Ther. 2005:3(1):131-9.

10. Ubani, Udo Ahanna. Common bacterial isolates from infected eye. J Niger Optom Assoc. 2009:15:40-7.

11. Willcox MD. Pseudomonas Aeruginosa infection and in ammation during contact lens wear. Optom Vis Sci. 2007:84(4):273-8.

12. Henry CR, Flynn W, Miller D, Forster RK, Alfonso EC. Infectious Keratitis progressing to Endophthalmitis: a 15-year-study of microbiology, associated factors, and clinical outcomes. Ophthalmology. 2012;119(12):2443-9.

13. Cao J, Yang Y, Yang W, Wu R, Xiao X, Yuan J, Xing Y, Tan X. Prevalence of infectious keratitis in Central China. BMC Ophthalmol. 2014;14:43.

14. Callegan MC, Gilmore MS, Gregory MS, Gregory M, Ramadan RT, Wiskur BJ, Moyer $\mathrm{AL}$, et al. Bacterial endophthalmitis: therapeutic challenges and host-pathogen interactions. Prog Retin Eye Res. 2007;26(2):189-203.

15. Epling J. Bacterial conjunctivitis. Clin Evid. 2012;2:704

16. Vaziri K, Stephen G, Krishna S, Harry K, Flynn W. Endophthalmitis: state of the art. Clin Ophthalmol. 2015:9:95-108.

17. Maheshwari R, Maheshwari S, Shah T. Acute dacryocystitis causing orbital cellulitis and abscess. Orbit. 2009:28:196-9.

18. Amin RM, Hussein FA, Idris HF, Hanafy F, Abdallah DM. Pathological, immunohistochemical and microbiological analysis of lacrimal sac biopsies in patients with chronic dacrocystitis. Int J ophthalmol. 2013;6(6):817-26.

19. Baron J, Miller JM, Weinstein M, Richter S, Gilligan P, Thomson B, et al. A guide to utilization of the microbiology Laboratory for Diagnosis of infectious diseases: 2013 recommendations by the Infectious Diseases Society of America (IDSA) and the American Society for Microbiology (ASM). Clin Infect Dis. 2013;57(4):e22-121.

20. Harbarth S, Samore MH. Antimicrobial resistance determinants and future control. Emerg Infect Dis. 2005;11(6):798-801.

21. Tesfaye, T, Beyene G, Gelaw Y, Bekele S and Saravanan M. Bacterial profile and antimicrobial susceptibility pattern of external ocular infections in Jimma University specialized hospital, Southwest Ethiopia. AJIGM. 2013; 1 (1):13-20.

22. Summaiya M, Neeta K, Sangita R. Ocular infections: rational approach to antibiotic therapy. Natl J Med Res. 2012;2(1):22-4.

23. Orlans $\mathrm{HO}$, Hornby SJ, Bowler ICJW. In vitro antibiotic susceptibility patterns of bacterial keratitis isolates in Oxford, UK: a 10-year review. Eye. 2011;25:489-93.

24. Baghani A, Sadeghian A, Bagheri M, Ghazvini K. The most common bacteria causing ocular infection in north-east of Iran between 2005-2011 and their antibiotic resistance pattern. Int J Microbiol Res Rev. 2013;2(7):118-21.

25. Reddy GP, Alam MR, Gopinathan U, Sharma S, Krishnaiah S. Comparision of vitro susceptibilities of gram-positive cocci isolated from ocular infections against the second and fourth generation quinolones at a tertiary eye care centre in South India. Eye. 2010;24:170-4.

26. Ansari MR, Madani H, Ghaderi E. Conjunctival bacterial flora and antibiotic resistance pattern in patients undergoing cataract surgery. Pak J Med Sci. 2008;24(4):581-5.

27. Mshangil B, Paddy M, Kajumbula H, Ateenyi-Agaba C, Kahwa B, Jeremiah SJ. External ocular surface bacterial isolates and their antimicrobial susceptibility patterns among pre-operative cataract patients at Mulago National Hospital in Kampala, Uganda. BMC Ophthalmol. 2013;13:71.

28. Long C, Liu B, Xu C, Jing Y, Yuan Z, Lin X. Causative organisms of posttraumatic endophthalmitis: a 20-year retrospective study. BMC Ophthalmol. 2014:14:34.

29. Simunovic MP, Rush RB, Hunyor AP, Chang AA. Endophthalmitis following intravitreal injection versus endophthalmitis following cataract surgery: clinical features, causative organisms and post-treatment outcomes. Br J Ophthalmol. 2012;96(6):862-6.

30. Friling $E_{\text {, Lundstrom } M}$, Stenevi $U$, Montan $P$. Six-year incidence of endophthalmitis after cataract surgery: Swedish national study. J Cataract Refract Surg. 2013;39(1):15-21.

31. Wallin $\mathrm{O}$, Abdullah M, Lundström M, Montan P. Endophthalmitis and severe blebitis following trabeculectomy. Epidemiology and risk factors; a single-centre retrospective study. Acta Ophthalmol. 2014;92(5):426-31.

32. Vola E, Moriyama S, Lisboa R, Vola M, Hirai E, Bispo M, Hofling-Lima L. Prevalence and antibiotic susceptibility of methicillin-resistant Staphylococcus Aureus in ocular infections. Arq Bras Oftalmol. 2013;76(6):350-3.

33. Chuang C-C, Hsiao C-H, Tan H-Y, Ma DH-K, Lin K-K, et al. Staphylococcus Aureus ocular infection: Methicillin-resistance, clinical features, and antibiotic susceptibilities. PLoS One. 2012;8(8):e42437. 
34. Walvick MD, Khan A. Ophthalmic methicillin-resistant Staphylococcus Aureus infections: sensitivity and resistance profiles of 65 isolates in centra California. ABB. 2013;4:263-5.

35. Tsironi E, Zacharaki F, Grivea N, Tachmitzi V, Michoula N, Vlychou M. European ST80 community-associated methicillin-resistant Staphylococcus Aureus orbital cellulitis in a neonate. BMC Ophthalmol. 2012;12:7.

36. Lalwani GA, Jr F, Scott IU, et al. Acute-onset endophthalmitis after clear corneal cataract surgery (1996-2005). Clinical features, causative organisms, and visual acuity outcomes. Ophthalmology. 2008;115(3):473-6.

37. Kuriyan AE, Weiss KD, Flynn W, Smiddy WE, Berrocal AM, Albini TA, Miller D. Endophthalmitis caused by streptococcal species: clinical settings, microbiology, management, and outcomes. Am J Ophthalmol. 2014;157(4):774-80.

38. Dias C, Gonçalves M, João A. Epidemiological study of hospital-acquired bacterial conjunctivitis in a level III neonatal unit. Sci World J. 2013;2013.

39. Kaliamurthy J, Kalavathy CM, Parmar P, Nelson Jesudasan CA, Thomas PA. Spectrum of bacterial keratitis at a tertiary eye care centre in India. BioMed research international. 2013;2013.

40. Assefa Y, Moges F, Endris M, Zereay B, Amare B, Bekele D. Bacteriological profile and drug susceptibility patterns in Dacryocystitis patients attending Gondar University teaching hospital, Northwest Ethiopia. BMC Ophthalmol. 2015;15:34.

41. Briscoe D, Rubowitz A, Assia E. Changing bacterial isolates and antibiotic sensitivities of purulent dacryocystitis. Orbit. 2005;24(2):95-8.

42. Cavuoto K, Zutshi D, Karp CL, Miller D, Feuer W. Update on bacterial conjunctivitis in South Florida. Ophthalmology. 2008;115(1):51-6.

43. Karsten E, Watson L, Foster R. Diversity of microbial species implicated in Keratitis: a review. Open Ophthalmol J. 2012;6:110-24.

44. Costantinides F, Luzzati R, Tognetto D, Bazzocchi G, Biasotto M, Tirelli C. Rapidly progressing sub periosteal orbital abscess:an unexpected complication of a group-a streptococcal pharyngitis in a healthy young patient. Head Face Med. 2012;8:28.

45. Sanders ME, Taylor S, Tullos N, Norcross E, Moore QC, Thompson H, et al. Passive immunization with Pneumovax W 23 and pneumolysin in combination with vancomycin for pneumococcal endophthalmitis. BMC Ophthalmol. 2013;13:8.

46. Bharathi JM, Ramakrishan R, Shivakumar C, Meenakshi R, Lionalraj D. Etiology and antibacterial susceptibility pattern of community-acquired bacterial ocular infections in a tertiary eye care hospital in south India. Indian J Ophthalmol. 2010;58(6):497-507.

47. Chhabra S, Kunimoto DY, Kazi L, Regillo CD, AC HO, Belmont J, et al. Endophthalmitis after open globe injury: microbiologic spectrum and susceptibilities of isolates. Am J Ophthalmol. 2006;142(5):852-4.

48. Callegan MC, Cochran DC, Kane ST, Ramadan RT, Chodosh J, Mclean C, et al. Virulence factor profiles and antimicrobial susceptibilities of ocular bacillus isolates. Curr Eye Res. 2007:31:693-702.

49. Jayasudha R, Narendran V, Manikandan P, Prabagarana SR. Identification of Polybacterial communities in patients with postoperative, posttraumatic, and 39 endogenous Endophthalmitis through 16S rRNA gene libraries. J Clin Microbiol. 2014;52(5):1459-66.

50. Hemavathi, Sarmah P and Shenoy P. Profile of Microbial Isolates in Ophthalmic Infections and Antibiotic Susceptibility of the Bacterial Isolates: A Study in an Eye Care Hospital, Bangalore. J Clin Diagn Res. 2014; 8(1):23-25. 38.

51. Al-Mezaine $\mathrm{H}, \mathrm{Al}$-Assiri A, Al-Rajhi A. Incidence, clinical features, causative organisms, and visual outcomes of delayed-onset pseudophakic endophthalmitis. Eur J Ophthalmol. 2008;19(5):804-11.

52. Whitcher JP, Cevallos V. Moraxella, down but not out-the eye bug that won't go away. Br J Ophthalmol. 2006;90:1215-6.

53. Shimizu Y, Toshida H, Honda R, Ohta T, Asada Y, Murakami A. Prevalence of drug resistance and culture-positive rate among microorganisms isolated from patients with ocular infections over a 4-year period. Clin Ophthalmol. 2013;7:695-702.

54. Alrawi AM, Chern KC, Cevallos V, Lietman T, Withcher JP, Margolis TP, Jr C. Biotypes and serotypes of Haemophilus influenzae ocular isolates. $\mathrm{Br}$ J Ophthalmol. 2002;86:276-7.

55. Justel M, Alexandre I, Martínez P, Sanz I, Rodriguez-Fernandez A, Fernandez I, et al. Vertical transmission of bacterial eye infections, Angola, 2011-2012. Emerg Infect Dis. 2015;21(3):471-3.

56. Mascarenhas J, Srinivasan M, Chen M, Rajaraman R, Ravindran M, Lalitha $\mathrm{P}$, et al. Differentiation of etiologic agents of bacterial keratitis from presentation characteristics. Int Ophthalmol. 2012;32(6):531-8.

57. Khosravi AD, Mehdinejad M, Heidari M. Bacteriological findings in patients with ocular infection and antibiotic susceptibility patterns of isolated pathogens. Singap Med J. 2007;48(8):741-3.
58. Patel M, Lavingia B, Patel A, Patel K. Susceptibility trends of pseudomonas in ocular infections. Gujarat Medical Journal. 2009;64(2):67-9.

59. Ly NC, Pham N, Badenoch R, Bell M, Hawkins G, Rafferty L. Bacteria commonly isolated from keratitis specimens retain antibiotic susceptibility to fluoroquinolones and gentamicin plus cephalothin. Clin Exp Ophthalmol. 2006;34:44-50.

60. Jebur S, Al-Hamadani AH, Sh J. Evaluation of genetic study and bacterial culture for diagnosis of Pseudomonal eye infections. Int J Curr Microbiol AppSci. 2015;4(3):348-56.

61. Rodriguez-Gonzalez F, Marrero-Saavedra D, Rutllan-Civit J, Cabrera-Vargas E, Martinez-Quintana E. Ocular necrotizing fasciitis due to Pseudomonas aeruginosa in a non-neutropenic patient. Saudi J Ophthalmol. 2013;27:281-2

62. Wong JS, Chan TK, Lee HM, Chee SP. Endogenous bacterial endophthalmitis: an east Asian experience and a reappraisal of a severe ocular affliction. Ophthalmology. 2000;107(8):1483-91.

63. Ji Y, Jiang C, Ji J, Luo Y, Jiang Y, Yi LY. Post-cataract endophthalmitis caused by multidrug-resistant Stenotrophomonas maltophilia:clinical features and risk factors. BMC Ophthalmol. 2015;15:14.

64. Corchia A, Limelette A, Hubault B, Robbins A, Quinquenel A, Bani-Sadr F, N'Guyen Y. Rapidly evolving conjunctivitis due to Pasteurella multocida, occurring after direct inoculation with animal droplets in an immunocompromised host. BMC Ophthalmol. 2015;15:21.

65. Muluye D, Wondimeneh Y, Moges F, Nega T, Ferede G. Types and drug susceptibility patterns of bacterial isolates from eye discharge samples at Gondar University hospital, Northwest Ethiopia. BMC Res notes. 2014;7:292.

66. Crounau H, Kankanala RR, Mauger T. Diagnosis and management of red eye in primary care. Am Fam Physician. 2010;81(2):137-44.

67. Chirinos-Saldana P, Lucio B, Hernandez-Camarena JC, Navas A, RamirezMiranda A, Vizuet-Garcia L. Clinical and microbiological profile of infectious keratitis in children. BMC Ophthalmol. 2013:13:54.

68. Givner LB. Periorbital versus Orbital cellulitis. Pediatr Infect Dis J. 2002; 21:1157-8.

69. Blanco C, Nunez MX. Antibiotic susceptibility of staphylococci isolates from patients with chronic conjunctivitis: including associated factors and clinical evaluation. J Ocul Pharmacol TH. 2013;29(9):803-8.

70. Stapleton F, Carnt N. Contact lens-related microbial keratitis: how have epidemiology and genetics helped us with pathogenesis and prophylaxis. Eye. 2012;26:185-93.

71. Falavarjani KG, Nekoozadeh S, Modarres M, Parvaresh M, Hashmi M, Soodi R, Alemzadeh SA. Isolates and antibiotic resistance of culture-proven Endophthalmitis cases presented to a referral Center in Tehran. Middle East Afr J Ophthalmol. 2012;19(4):361-3.

72. Das S, Constantinou M, Daniell M, Taylor HR. Moraxella keratitis: predisposing factors and clinical review of 95 cases. Br J Opthalmol. 2006:90:1236-8

73. Wiskur BJ, Hunt JJ, Callegan MC. Hypermucoviscosity as a virulence factor in experimental Klebsiella Pneumoniae Endophthalmitis. Invest Ophthalmol Vis Sci. 2008;49(11):4931-8.

74. Abdullah FE, Khan MI, Waheed S. Current pattern of antibiotic resistance of clinical isolates among conjunctival swabs. Pak J Med Sci. 2013;29(1):81-4.

75. Sherwal BL, Ak V. Epidemiology of ocular infection due to bacteria and fungus - a prospective study. JK Sci. 2008;10(3):127-31.

76. Namitha BN, Mahalakshmi RA. Aerobic Bacteriological Profile in Cases of Ocular Infections in a Tertiary Care Hospital (Navodaya Medical College and Research Centre, Raichur). IOSR-JDMS. 2014:13(11):14-21.

77. Amsalu A, Abebe T, Mihre A, Delelegn D, Tadess E. Potential bacterial pathogens of external ocular infections and their antibiotic susceptibility pattern at Hawassa university teaching and referral hospital, southern Ethiopia. Afr J Microbiol Res. 2015;9(14):1012-119.

78. Haas J, Larson E, Ross B, See B, Saiman L. Epidemiology and diagnosis of hospital-aquired conjunctivitis among neonatal intensive care unit patients. Pediatr Infect Dis J. 2005:24(7):586-9.

79. Rahman ZA, Harun A, Hasan H, Mohamed Z, Noor SS, Deris ZZ, Ismail N, Hassan AS, Ahmad F, Yaakub A. Ocular surface infections in northeastern state of malaysia: A 10-year review of bacterial isolates and antimicrobial susceptibility. Eye Contact Lens. 2013;39(5):355-60.

80. Miller D. Update on the epidemiology and antibiotic resistance of ocular infections. Middle East Afri J Ophthalmol. 2017;24(1):30-42.

81. Rahimi F, Hashemian MN, Khosravi A, Moradi G, Bamdad S. Bacterial Keratitis in a tertiary eye Centre in Iran:a retrospective study. Middle East Afri J Ophthalmol. 2015;22(2):238-44. 
82. Politis M, Wajnsztajn D, Rosin B, Block C, Solomon A. Trends of bacterial Keratitis culture isolates in Jerusalem: a 13 -years analysis. PLoS One. 2016; 11(11):e0165223.

83. Bourcier T, Thomas F, Borderie V, Chaumeil C and Laroche L. Bacterial keratitis: predisposing factors, clinical and microbiological review of 300 cases. Br J Ophthalol. 2003;87:834-8.

84. Kampitak K, Suntisetsin H, Sirikul T. Clinical and microbiological characteristics of corneal ulcers in a Thai referral center. Asian Biomed. 2014; 8(2):275-82.

85. Moriyana AS, Hofling-lima AL. Contact lens-associated microbial keratitis. Arq Bras Oftalmol. 2008;71(6 Supl):32-6.

86. Jyoti S, Kumar SA, Priyanka T, Nandan SB, Ramesh Y. Conjunctival microflora and their antibiotic susceptibility in north Indians prior to cataract surgery. Int J Curr Microbiol App Sci. 2014;3(9):254-9.

Submit your next manuscript to BioMed Central and we will help you at every step:

- We accept pre-submission inquiries

- Our selector tool helps you to find the most relevant journal

- We provide round the clock customer support

- Convenient online submission

- Thorough peer review

- Inclusion in PubMed and all major indexing services

- Maximum visibility for your research

Submit your manuscript at www.biomedcentral.com/submit
Biomed Central 